\title{
Sharp Injuries and Associated Factors Among Health Care Professionals in Western Wollega Public Hospitals, West Ethiopia
}

\author{
Yohannes Bacha Gemechu \\ Department of Nursing, College of Medicine and Health Sciences, Ambo University, Ambo, Ethiopia
}

Email address:

injoo1788@gmail.com

\section{To cite this article:}

Yohannes Bacha Gemechu. Sharp Injuries and Associated Factors Among Health Care Professionals in Western Wollega Public Hospitals, West Ethiopia. American Journal of Clinical and Experimental Medicine. Vol. 8, No. 5, 2020, pp. 82-89. doi: 10.11648/j.ajcem.20200805.12

Received: September 17, 2020; Accepted: October 6, 2020; Published: November 23, 2020

\begin{abstract}
Background: Sharp injuries (SIs) are wounds caused by sharp instruments accidentally puncturing the skin. Hence, the objective of this study was to assess magnitude of sharp injuries and associated factors among health care professionals in western "wollega" public Hospitals, west Ethiopia. Methods: Facility based cross- sectional study design was used in western "Wollega" zone public hospitals from February 10 to March 12, 2015. All health care professionals available during the study period were included in the study. Data were entered in to SPSS for windows version 16.0 for analysis. Multivariable logistic regression model was done to identify independent effects of each predictor. Result: The prevalence of sharp injuries among health care professionals in western wollega public hospitals is 56 (32.9\%). The prevalence of sharp injuries was higher among diploma nurses (40.5\%), followed by laboratory technicians and diploma midwifery respectively. The sharp injuries experienced in the last one year were related to recapping of needle (53.6\%), 48.2\% during suturing, and failure to adhere to Universal precautions (33.9\%). The multivariate logistic regression analysis showed that the most important risk factor for sharp injuries were lack of training (Adjusted Odds Ratio=15.6), working experience $<5$ years (Adjusted Odds Ratio=9.17), $>10$ injection per day (Adjusted Odds Ratio=13), working more than 35 hours per week (Adjusted Odds Ratio=8.22), negative attitude $(A O R=8.6)$, poor practice of universal precautions (Adjusted Odds Ratio=6.6), night shift work (Adjusted Odds Ratio=6.6) and recapping of needle most of the time (Adjusted Odds Ratio=9.9). Conclusion and recommendation: The prevalence of sharp injury in western wollega public hospitals is $56(32.9 \%)$ within the last one year. Lack of training, hours worked per week, number of injection per day, work experience, poor practice, negative attitude, night shift work and recapping of needle were identified as risk factors for sharp injuries. Further prospective studies on large scale are recommended to determine the cause and effect relationship of factors affecting sharp injuries among HCPs in hospital setting.
\end{abstract}

Keywords: Sharp, Injury, Needle, Predictors, Prevalence

\section{Introduction}

Accidental occupational injuries to health care workers (HCWs) continue to have a significant problem in healthcare system owing to the associated health risk of acquiring infections such as hepatitis B (HBV), hepatitis C (HCV) and human immunodeficiency (HIV) viruses. [1, 2]

The worldwide incidence of percutaneous injury with a sharp object among the HCWs is estimated to be 3 million every year where a chance of four injuries per healthcare worker could occur annually $[5,6]$. Exposure to unsafe blood as a consequence of the injury may have a risk of infections to human immunodeficiency virus (HIV), hepatitis B (HBV), hepatitis $\mathrm{C}(\mathrm{HCV})[3,4]$.

Sharps are any device or object used to puncture or lacerate the skin in patient care, which includes used items like syringes and needles, intravenous tubing with needles attached, giving sets, scalpel blades, knives, lancets, blades and broken glass. [5]

Sharp injuries are wounds caused by sharp instruments accidentally puncturing the skin. Injuries are commonly associated with the disassembly of devices such as vacuum 
blood taking systems or intravenous cannula, recapping of needles; transfer of used sharps to point of disposal; sharps not discarded after use or overfilled sharps container [6].

The workers in the health care facility do not take care of the hazards associated with sharp injuries; they do not provided with or properly utilize protective gears like gloves, face masks and boots. On the other hand some sharps users throw their used needles in the trash or flush them down the toilet which consequently result in hurting sanitation workers during collection rounds. [7].

Sharps waste management is a major problem in most developing countries due to its ever growing and endless generation. Syringes and needles are of particular concern because they constitute an important part of the sharps waste and often are contaminated with body fluids from patients [8].

In developing countries including Ethiopia in general and the study area in particular there is a lack of information related to sharp injuries and its associated factors. Thus; the purpose of this study is to assess Sharp Injuries and associated factors among Health Care professionals in Western Wollega Public Hospitals.

The Occupational Safety and Health Administration states that a healthcare worker is injured by a sharp/penetrating item every second in the world and as a result one million healthcare workers are injured by contaminated sharp items annually $[9,10]$.

For example an estimated 600,000 to 800,000 hospital sharps injuries occur in the USA each year, up to one-third of nursing and laboratory staff experiencing sharp injuries in Canada,22.2 incidents per 1000 healthcare workers at a regional hospitals in Singapore [11], 500,000 needle stick injuries occur annually in Germany [12], the number of sharp and needle stick injuries per person among healthcare staff is 4 per year in Africa, Western Mediterranean and Asia [13] and the number of HCWs annually exposed to sharps injuries contaminated with $\mathrm{HBV}, \mathrm{HCV}$, and $\mathrm{HIV}$, is estimated at 2.1 million, 926,000 and 327,000, respectively [14].

$\mathrm{HBV}, \mathrm{HCV}$, and HIV are the most commonly transmitted pathogens during patient care $[5,11]$. The most common cause of injury was needle stick, which accounted for $63 \%$ of all incidents. For instance, CDC estimates that each year 385,000 needle sticks and other sharps related injuries are sustained by hospital-based health care personnel; an average of 1,000 sharps injuries per day and it occurred most frequently during patient treatment $(46 \%)$ followed by surgery $(15 \%)$ and cleansing medical equipment $(7 \%)[6,11]$.

Factors that contribute to sharp injuries are lack of safety devices, inconveniently placed or overfilled sharps disposal containers, recapping of needles, lack of awareness of hazard, lack of training, lack of supplies, working long hours, night shift work, and number of injections administered per day [15].

A survey of physicians, nurses, and medical technologists published in 2003 found that many healthcare workers do not follow Standard Precautions. Approximately one-third reported not wearing gloves during an invasive procedure, 30 to 71 percent would recap a needle after use, and 46 to 68 percent did not always wash their hands after patient care [16].

The World Health Organization has estimated that exposure to sharps in the workplace accounts for $40 \%$ of infections with HBV and HCV and $2-3 \%$ of HIV infections among health care workers [17]. The occupational risk of needle stick injuries are not only affects the quality of care delivered but also the safety and well-being of care providers. [17].

Sharp injuries often have severe consequences both physically and mentally. For instance, occupational infection with HIV, HBV and HCV may have serious consequences. The risk of infection with HBV, HCV and HIV from SIs has been estimated to vary from $6 \%$ to $30 \%$, from $3 \%$ to $10 \%$, and about $0.4 \%$, respectively $[18,20]$.

Despite a growing awareness of the dangers posed by sharp injuries to healthcare workers, there is a critical shortage of information on magnitude and factors determining risks having of sharp injuries among health care workers in study area.

Therefore, the purpose of this study is to identify sharp injuries and associated factors among health care professionals in western "wollega" zone public hospitals.

\section{Methods and Subjects}

A facility based cross- sectional study conducted in western "wollega" public hospitals (Ghimbi, Nedjo and Begi hospital), from February 10 to March 12, 2015. Ghimbi, Nedjo and Begi town is located $441 \mathrm{Km}, 515 \mathrm{~km} \mathrm{\& 721 \textrm {km }}$ away from the capital city Addis Ababa to the west. The hospital has a total of 211 health care professionals. All health care professionals who are present at work during the study period and are involved in the direct day-to-day management of patients during the last one year were included and health care professionals who are in general administrative positions were excluded.

Data were collected by self-administered structured questionnaires which comprised of socio-demographic characteristics like age, sex, marital status, religion, professional qualification, work experience; Enabling factors such as training on Ups, knowledge of Ups, presence of guidelines, attitudes, practices of Ups and availability of sharp waste disposal material, PPE; Work related factors such as number of injection per day, working hours per week, working time, working unit, needle recapping and suturing.

The data were checked for its completeness, accuracy, clarity and consistence every day by the investigator. Finally, the data were entered to a computer and analyzed using SPSS for windows version 16.0 software. The study was approved by the Student Research Program of Jimma University and verbal informed consent was obtained from individuals by explaining the purpose of the study and no obligation or force was imposed on the study subjects.

The following operational definitions were used in this study. 
Attitude: had 15 questions. Scoring for each statement was as follows: [19]. Scores ranged from 15 to 60 .

The total score was categorized into two groups:

Positive attitude=total score which is equal to or more than the median points in the questionnaire.

Negative attitude=total score which is less than the median points in the questionnaire.

Practice: assessed by asking about using appropriate equipment and applying UPs, and after using sharp medical equipment (asking about recapping). [19].

The total score was classified into two categories.

Poor practice: a total score, which is less than the median points in the questionnaire.

Good practice: a total score, which is equal to, or more than the median points in the questionnaire.

Level of knowledge: The total score of the knowledge is classified into three categories [19].

Poor: he/she scored $<60 \%$ points in the knowledge questionnaire

Fair: he/she scored $60 \%-80 \%$ points in the knowledge questionnaire

Good: he/she scored $>80 \%$ points in the knowledge questionnaire

\section{Results}

Out of 170 , the majority $96(56.5 \%)$ were female, 80 $(47.1 \%)$ were in age range of $20-29$ years, $92(54.1 \%)$ of them were single, $102(60 \%)$ had work experience of $<5$ years and 92 (54.1\%) were diploma holders. (Table 1).

Table 1. Distribution of health care professional's by Socio-demographic characteristics in western wollega public hospitals, west Ethiopia, May. 2012

\begin{tabular}{llll}
\hline & & Number $(\mathbf{N}=\mathbf{1 7 0})$ & $\mathbf{\%}$ \\
\hline \multirow{4}{*}{ Age } & 20-29 years & 80 & 47.1 \\
& 30-39 years & 50 & 29.4 \\
& 40-49 years & 30 & 17.6 \\
Sex & $+>50$ years & 10 & 5.9 \\
& Male & 74 & 43.5 \\
Marital status & Female & 96 & 56.5 \\
& Single & 92 & 54.1 \\
Qualifications & Married & 78 & 45.9 \\
Work & BSc & 63 & 37.1 \\
experience & Diploma & 107 & 62.9 \\
\hline
\end{tabular}

The prevalence of sharp injuries among health care professionals in western Wollega is $56(32.9 \%)$ within the last one year. From these, $7.6 \%$ reported having experienced at least one needle-stick injuries, while $14.1 \%$ reported two needle-stick injury and $11.2 \%$ reported three times and more in the last 6 months. About $67.1 \%$ had not experienced any such injury in their entire career.

The prevalence of sharp injuries was higher among diploma nurses $(40.5 \%)$, followed by $33.3 \%, 16.6 \%$ among laboratory technicians and diploma midwifery respectively.

The most commonly reported causes for sharp injuries in the last one year were scalpel needles $(60.7 \%)$ followed by syringe needle $(55.4 \%)$. (Table 2$)$

Table 2. Items that causes sharp injuries among health care professionals in western Wollega public hospitals, West Ethiopia, May. 2012.

\begin{tabular}{lll}
\hline Items responsible for SIs & Frequency $(\mathbf{N}=\mathbf{1 7 0})$ & Percent \\
\hline Scalpel needles & 34 & 60.7 \\
Syringe needle & 31 & 55.4 \\
blood collection needles & 27 & 48.2 \\
broken ampoule/glass items & 20 & 35.7 \\
Hypodermic needles & 19 & 33.9 \\
Lancet & 19 & 33.9 \\
IV cannula & 13 & 23.2 \\
\hline
\end{tabular}

*The percentages do not add up to 100 as multiple responses are possible.

The activities associated with sharp injuries in the last one year were recapping of needle $(53.6 \%), 48.2 \%$ during suturing, and failure to adhere to Ups (33.9\%). (Table 3)

Activities related to sharp injuries: the activities associated with sharp injuries in the last one year were recapping of needle $(53.6 \%), 48.2 \%$ during suturing, and failure to adhere to Ups (33.9\%). (Table 3)

Table 3. Factors associated with SIs at work place among health care professionals in western wollega public hospitals, West Ethiopia, May. 2012.

\begin{tabular}{lll}
\hline Risk factors for SIs & $\begin{array}{l}\text { Frequency } \\
(\mathbf{N = 1 7 0 )}\end{array}$ & percent \\
\hline Recapping of needle & 30 & 53.6 \\
Suturing & 27 & 48.2 \\
Failure to adhere to Ups & 18 & 32.1 \\
Blood withdrawal & 21 & 37.5 \\
Lack of access to and failure to use sharps & 21 & 37.5 \\
containers immediately after injection & 18 & 32.1 \\
Did not know how to prevent sharp injury & 14 & 25 \\
Handling needles on sharp tray & 14 & 25 \\
Placing of needle in a full container & & \\
\hline
\end{tabular}

*The percentages do not add up to 100 as multiple responses are possible.

Twenty-three $(41.1 \%)$ of SIs to HCPs were occurred when the procedure was being done, after needle was used for intended purpose, and during operation theatre process. (Table 4)

Table 4. Shows time of sharps injury occurrence in western wollega public hospitals, West Ethiopia, May. 2012.

\begin{tabular}{lll}
\hline When the injury occurred & $\begin{array}{l}\text { Frequency } \\
\text { (N=170) }\end{array}$ & percent \\
\hline While recapping used needle & 29 & 51.8 \\
During operation theatre process & 27 & 48.2 \\
During disposal & 25 & 44.6 \\
After needle was used for intended purpose & 22 & 39.3 \\
When the procedure was being done & 23 & 41.1 \\
While putting item into disposal container & 13 & 23.2 \\
While withdrawing a needle from resistant & 14 & 25 \\
material & & \\
\hline
\end{tabular}

*The percentages do not add up to 100 as multiple responses are possible.

Regarding working area, the majority $(42.9 \%)$ of SIs was occurred in patient room followed by delivery room (39.3\%) (Figure 1). 


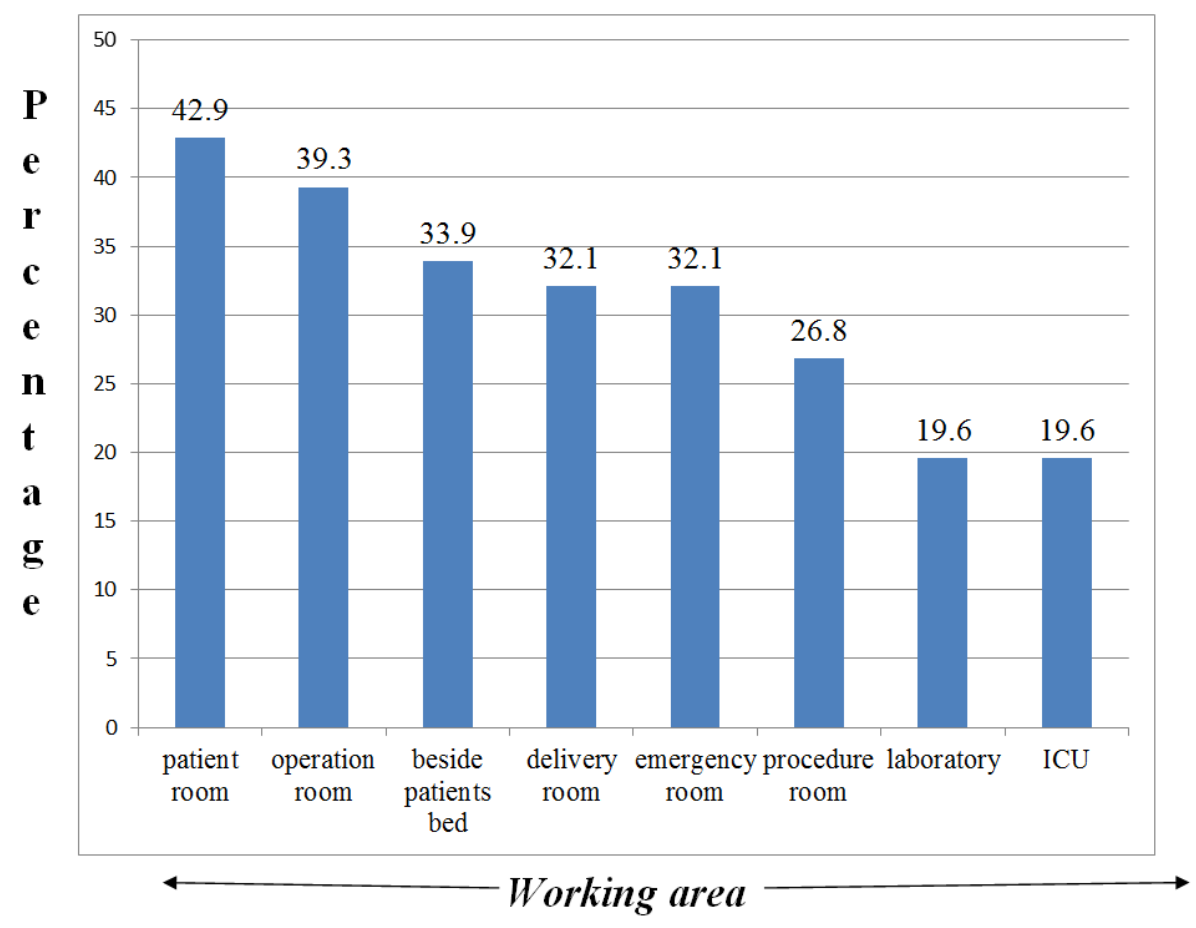

*The percentages do not add up to 100 as multiple responses are possible.

Figure 1. Prevalence of sharps injuries by working area among health care professionals in western wollega public hospitals, west Ethiopia, may. 2012.

\subsection{Factors Associated with Sharp Injuries}

\subsubsection{Enabling Factors}

From $170 \mathrm{HCPs}$, about two-third $115(67.6 \%)$ were not trained about UP prior to work, $94(55.3 \%)$ reported unavailability of safety boxes in the wards, $113(66.5 \%)$ were not trained about sharp injury at work place and majority of the respondents, $106(62.4 \%)$ were not taking training on prevention of sharp injuries.

\subsubsection{Knowledge about Universal Precautions}

The results show that almost all of the subjects were aware about the transmission of HIV, $167(98.2 \%), \mathrm{HBV}, 160$ (94.1\%) and HCV, 159 (93.5\%) by sharp injury and the risks associated with sharp injury. This result showed that 94 $(55.3 \%)$ of the respondents knew the hospital policy on disposal of sharps medical wastes and $100(58.8 \%)$ knew prevention of SI. However, 76 (44.7\%) and $70(41.2 \%)$ were not aware about hospital policy and prevention of SI respectively.

The results show that majority stated that were aware about universal precaution guideline $161(94.1 \%)$ and 91 (53.5\%) were vaccinated against HBV. One hundred fifty three $(90 \%)$ of the respondents were aware about safety precautions, whereas $17(10 \%)$ were not aware. Among them, $165(97.1 \%)$ aware about hand washing practice, 107 (62.9\%) about PPE, 80 (47.1\%) about PEP, and 74 (43.5\%) disposing sharps wastes.

Generally, $36(21.2 \%), 58(34.1 \%)$ and $76(44.7 \%)$ of the respondents have poor, fair and good knowledge towards safety precaution respectively (Figure 2).

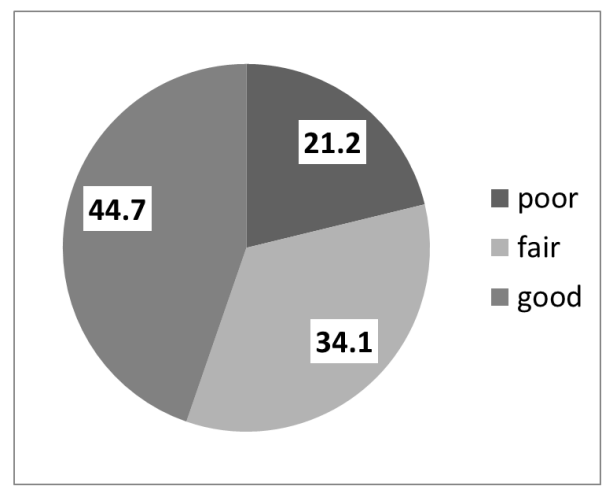

Figure 2. Knowledge of health care professionals on safety precautions in western wollega public hospitals, west Ethiopia, May 2012.

\subsubsection{Practices of UPS}

Twenty two (12.9\%) of respondents always wearing gloves and gowns during procedures, $12.4 \%$ quite often, $41.2 \%$ sometimes, $21.2 \%$ rarely and $12.4 \%$ very rarely. While 57 $(33.5 \%)$ were always wearing gloves and gowns during handling needles and syringe, $30 \%$ sometimes, and 62 $(36.5 \%)$ rarely / very rarely and $63(37.1 \%)$ of the respondents were always/ quite often wearing gloves and gown while giving injection, $70(41.2 \%)$ sometimes and 37 $(21.8 \%)$ were wearing rarely/very rarely.

Sixty-two $(36.5 \%)$ of HCPs were always/quite often, 41 (24.1\%) sometimes, $67(39.4 \%)$ rarely/very rarely following UPs. Sixty-one (35.9\%) percent respondents recap the needle quite often/ always, 46 (27.1\%) sometimes, and 63 (37.1\%) rarely/very rarely. Eighty-seven (51.2\%) of HCPs were always wearing gloves during withdrawing needles from 
patient, 33 (19.4\%) some times, and 50 (29.4\%) were wearing gloves rarely/very rarely.

Fifty-seven (33.7\%) of HCPS were always/quite often wearing gloves during manipulating sharp, 66 (38.8\%) sometimes and 47 (27.6\%) were wearing gloves rarely. Seventy-five (44.1\%) of HCPs were always wearing gloves during disposal contaminated needles or sharps, 46 (27.1\%) some times and 49 (28.8\%) were wearing rarely. (Table 5)

Table 5. Practice of Ups among health care professionals in western wollega public hospitals, West Ethiopia, May. 2012.

\begin{tabular}{|c|c|c|c|}
\hline Variables & & Number $(N=170)$ & Percent \\
\hline \multirow{3}{*}{ Wearing gloves and gowns during procedures } & Always/Quite often & 43 & 25.3 \\
\hline & Sometimes & 70 & 41.2 \\
\hline & Rarely/ very rarely & 57 & 33.5 \\
\hline \multirow{3}{*}{$\begin{array}{l}\text { Wearing gloves during handling syringe and } \\
\text { needles }\end{array}$} & Always/Quite often & 57 & 33.5 \\
\hline & Sometimes & 51 & 30 \\
\hline & Rarely/ very rarely & 62 & 36.5 \\
\hline \multirow{2}{*}{ Wearing gloves during giving injection } & Always/Quite often & 63 & 37.1 \\
\hline & Rarely/ very rarely & 37 & 21.8 \\
\hline \multirow{3}{*}{ Following UPs } & Always/Quite often & 62 & 36.5 \\
\hline & Sometimes & 41 & 24.1 \\
\hline & Rarely/ very rarely & 67 & 39.4 \\
\hline \multirow{3}{*}{ Needle recapping } & Always/Quite often & 61 & 35.9 \\
\hline & Sometimes & 46 & 27.1 \\
\hline & Rarely/ very rarely & 63 & 37.1 \\
\hline $\begin{array}{l}\text { Wearing gloves and gowns while withdrawing } \\
\text { needle from patient }\end{array}$ & Rarely/ very rarely & 50 & 29.4 \\
\hline \multirow{3}{*}{ Wearing gloves while manipulating needles } & Always/Quite often & 57 & 33.7 \\
\hline & Sometimes & 66 & 38.8 \\
\hline & Rarely/ very rarely & 47 & 27.6 \\
\hline \multirow{3}{*}{$\begin{array}{l}\text { Wearing gloves during disposal of contaminated } \\
\text { sharps }\end{array}$} & Always/Quite often & 75 & 44.1 \\
\hline & Sometimes & 46 & 27.1 \\
\hline & Rarely/ very rarely & 49 & 28.8 \\
\hline
\end{tabular}

This result showed that the majority of the respondents were scored less than the median point $(<30 / 60)$ in the questionnaire of practice on universal precaution and disposal of sharp wastes. Among the respondents, majority,
$110(64.7 \%)$ were poorly practice Ups and sharps medical waste disposal, whereas, $60(35.3 \%)$ were good to practice Ups and in disposing of sharps medical wastes. (Figure 3)

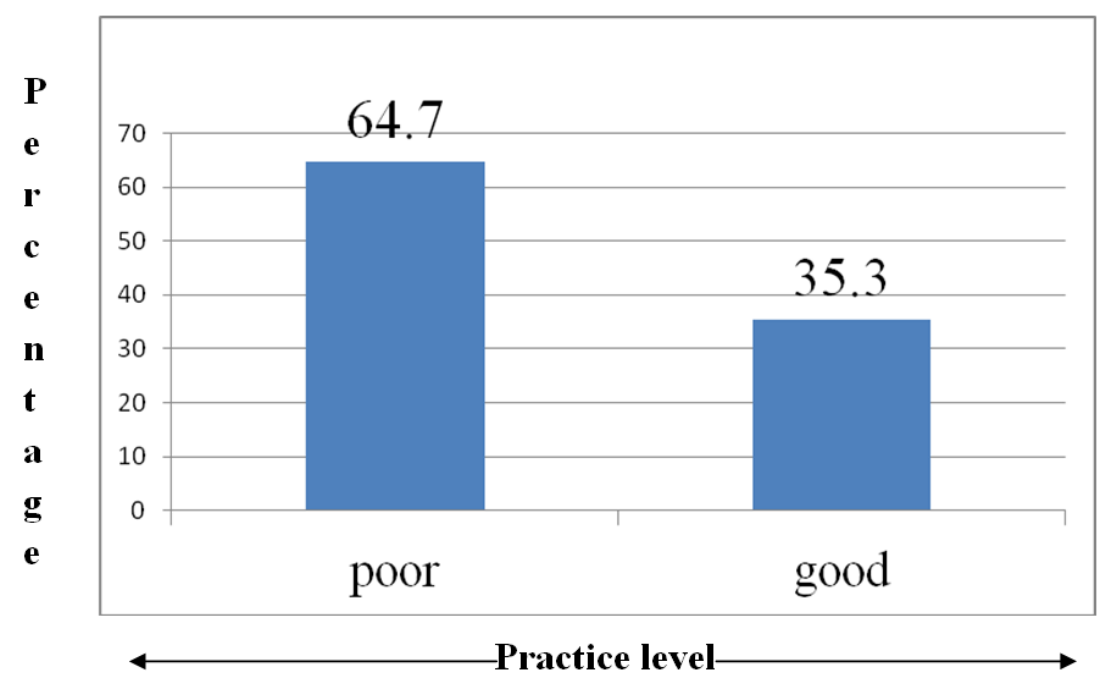

Figure 3. Level of practices of UPs among health care workers in western wollega public hospitals, West Ethiopia, May. 2012.

Among HCPs poorly practice Ups and sharps medical waste disposal, 42 (38.2\%) were sustained from SIs, whereas only $14(23.3 \%)$ were sustained SIs among HCPs with good practice. This finding showed that although majority (94.1\%) stated that they know about universal precaution guidelines, however, there are gaps in the knowledge and practice.

\subsubsection{Attitude of HCPS Towards ups}

Among 170 HCPs involved in the study, 72 (42.4\%) had negative attitude towards Ups and prevention of sharp injuries whereas $98(57.6 \%)$ had positive attitude. (Figure 4). From $72(42.4 \%)$ with negative attitude towards Ups and prevention of sharp injuries, $42(58.3 \%)$ were sustained from 
sharp injury.

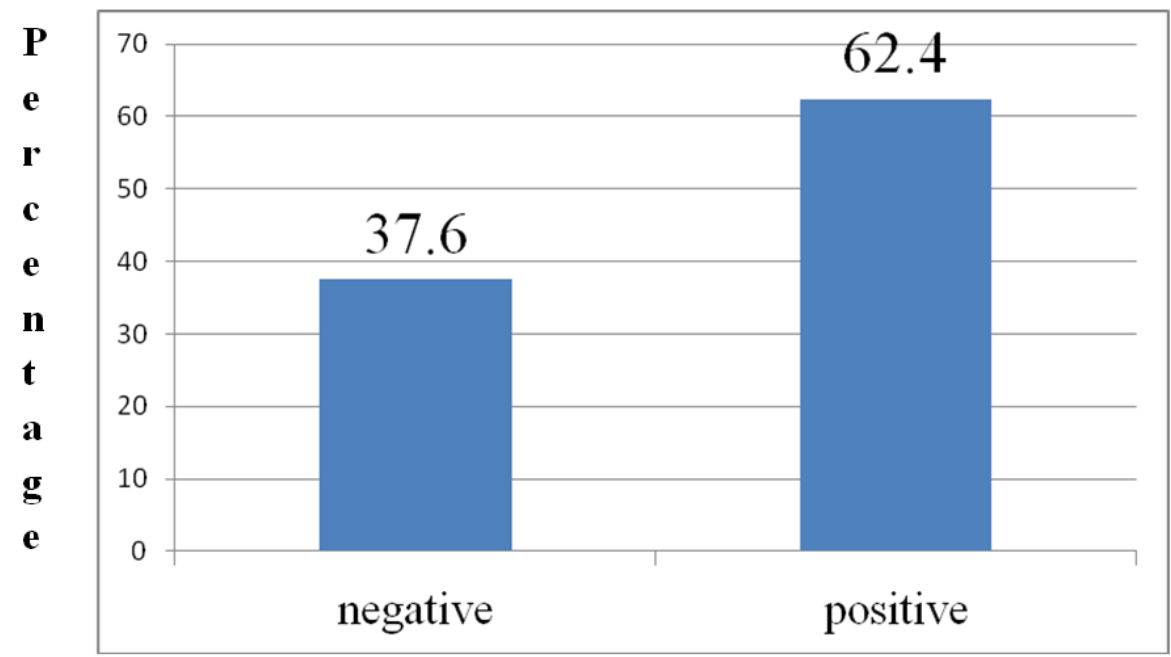

\section{Attitude level}

Figure 4. Attitude of HCPs towards Ups in western wollega public hospitals, May 2012.

Table 6. Knowledge, Practice, Attitude and sharp injuries cross tabulation among HCPs in western wollega public hospitals, May 2012.

\begin{tabular}{llll}
\hline & & \multicolumn{2}{l}{ Sharp injury } \\
\cline { 3 - 4 } & & Yes & No \\
\hline \multirow{3}{*}{ Knowledge } & poor & $16(44.4 \%)$ & $20(55.6 \%)$ \\
& Fair & $19(32.8 \%)$ & $39(67.2 \%)$ \\
\multirow{3}{*}{ Attitude } & Good & $21(27.6 \%)$ & $55(72.4 \%)$ \\
& Negative & $42(58.3 \%)$ & $30(41.7 \%)$ \\
Practice & Positive & $23(23.2 \%$ & $76(76.8 \%)$ \\
& Poor & $46(41.4 \%)$ & $65(58.6 \%)$ \\
& Good & $10(16.9 \%)$ & $49(83.1 \%)$ \\
\hline
\end{tabular}

\subsubsection{Working Factors}

Out of 170 HCPs involved in the study, majority, 108 $(63.5 \%)$ HCPs were worked $>35$ hours per week, 134 (78.8\%) of them give $>10$ injections per day, and 73 (42.9\%) were worked nightshifts at the study period. Regarding their working unit, $36(31.2 \%)$ was working in surgical ward, 30 $(17.6 \%)$ were working in medical ward, and $22(12.9 \%)$ were working in the MCH. (Table 7)

Table 7. Working conditions of health care professionals in western wollega public hospitals, May 2012.

\begin{tabular}{llll}
\hline Variables & & No (170) & \% \\
\hline \multirow{2}{*}{ working Hours per week } & $<35$ hours & 62 & 36.5 \\
& $\geq 35$ hours & 108 & 63.5 \\
Number of injection per day & $1-10$ & 36 & 21.2 \\
& $>10$ & 134 & 78.8 \\
Working time & Night & 73 & 42.9 \\
& Day & 97 & 57.1 \\
& Medical ward & 30 & 17.6 \\
& Surgical ward & 36 & 21.2 \\
& ER & 20 & 11.8 \\
Working unit & ICU & 19 & 11.2 \\
& Laboratory & 5 & 2.9 \\
& MCH & 22 & 12.9 \\
& Pediatric & 20 & 11.8 \\
& OR & 18 & 10.6 \\
\hline
\end{tabular}

The occurrence of SIs was different across specialty with in different working units.

\subsection{Predictors of Sharp Injuries}

Bivariate logistic regression analysis shows that the prevalence of SIs was significantly associated with practice level: HCPs who were poorly practice UPs were 3.4 times more likely to sustain from SIs than HCPs who had good practice habit with COR of 3.4, SIs were almost 4.5 times more likely to occur among health care workers who worked longer than 35 hours per week with COR of 4.52 and Sharp injuries were 3.5 more prevalent in HCPs who were not trained about Ups prior to work. Compared to health care workers who gave less than 10 injections, the likelihood of experiencing SIs was about 5 times more likely among those who administer more than 10 injections per day with COR of 5.07, SIs were 8.5 more likely to occur among HCP who were not provided with training at work as compared to those who were provided with training with COR of 8.555 . Sociodemographic factors such as age and sex are only predicting sharp injury on binary logistic regression, but loose their significance when adjusted for other variables. In this analysis ethnicity, religion and marital status are not significant predictors of sharp injuries.

The multivariate logistic regression analysis showed that the important risk factor for sharp injuries was lack of training with AOR of 15.6, working for more than 35 $\mathrm{h} /$ weeks with AOR of 8.2, training about Ups prior to work with AOR of 7.75, recapping needles quite often / always with AOR of 9.9, poor Ups practice with AOR of 6.61, having night shifts with AOR of 6.64 and negative attitude with AOR of 8.6. Lack of training on SIs at work place, having night shifts, attitude and working hours per week were highly associated with occurrence of SIs $(p<0.05)$. 
Table 8. Predictors of SIs among health care professionals in western wollega public hospitals, west Ethiopia, May. 2012.

\begin{tabular}{llll}
\hline Variables & & COR $(\mathbf{9 5 \%} \mathbf{C I})$ & AOR (95\% CI) \\
\hline \multirow{2}{*}{ Work experience } & $\leq 5$ yrs & $2.375(1.183-4.766)^{* *}$ & $9.174(1.79-46.9)^{* *}$ \\
& $>5$ years & 1 & 1 \\
Working hours per week & $\leq 35$ & 1 & 1 \\
& $>35$ & $4.523(1.962-10.428)^{* *}$ & $8.225(1.54-43.7)^{* *}$ \\
Working time & Night & $12.56(5.73-27.55)^{* *}$ & $6.644(1.5-29.2)^{* *}$ \\
& Day & 1 & 1 \\
Number of injections per day & $1-10$ & 1 & 1 \\
Training about Ups & $>10$ & $5.073(1.696-15.179)$ & $13(1.33-23.7)^{* *}$ \\
prior to work & Yes & 1 & 1 \\
& No & $3.533(1.579-7.904)^{* *}$ & $7.75(1.24-48.14)^{* *}$ \\
Recapping needles & Rarely & 1 & 1 \\
& Sometimes & $4.782(1.252-17.182)^{*}$ & $7.86(2.098-15.89)^{*}$ \\
Practice level & Always & $8.600(3.529-20.960)^{* *}$ & $9.93(1.8-52.7)^{* *}$ \\
Training at & poor & $3.345(1.536-7.286)$ & $6.61(1.43-30.46)^{* *}$ \\
work on SI & Good & 1 & 1 \\
Attitude & Yes & 1 & 1 \\
& No & $8.555(3.180-23.015)$ & $15.6(5.113-34.9)^{* *}$ \\
\hline
\end{tabular}

$\left({ }^{* *}\right.$ statistically significant at $\mathrm{p}<0.001 *$ statistically significant at $\left.\mathrm{p}<0.01\right)$.

\section{Discussion}

This study showed that the overall prevalence of SI among health care professionals in western wollega public hospitals is $32.9 \%$. This is similar with studies done in Sidama zone, Hawasa and Northwestern Ethiopia in which $32 \%, 30 \%$ and $31 \%$ of the sharp injuries were reported respectively. From $32.9 \%$ of incidence of SIs, $7.6 \%$ reported having experienced at least one sharp injury, while $14.1 \%$ reported two sharp injury and $11.2 \%$ reported three times and more in the last 6 months. This is slightly similar with study conducted in Mongolia in which the frequency of incidence was once for $14.7 \%$, twice for $11.0 \%$, and three times or more for $12.6 \%$.

The result of this study has shown female predominated among health care professionals with sharp injuries (46.9\%) and that is explained by the fact that the vast majority of health care professionals in the hospitals are female in gender.

In this results $35.3 \%, 37.6 \%$ and $27.1 \%$ of the respondents have poor, fair and good knowledge towards safety precaution respectively. It is almost similar with study conducted in Indonesian teaching hospital in which knowledge of UP was fairly good; knowledge of hand washing, personal protective equipment, medical waste disposal and post exposure prophylaxis was high.

However, knowledge of medical sharps disposal was poor [7]. This discrepancy may be due to overcrowded work place, lack of experience and different study setting. This finding showed that although majority (94.1\%) stated that they know about universal precaution guidelines, however, there are gaps in the knowledge and practice. This gap may be due to lack of training, lack of supervision and ignorance.

Sixty three percent $(63 \%)$ respondents recap the needle quite often, always and sometimes. This was slightly higher than study done in Hawasa in which $57.1 \%$ recap needle most of the time, all of the time and sometimes [16] and in India in which $59.3 \%$ of HCWs were always recapping the needle after injection [15]. This difference may be due to different in sociodemographic characteristics, study sites and not having recommended practice in this study site. The most commonly reported items that cause SI in the last one year were syringe needles $(55.4 \%)$, and broken ampoule/glass items (35.7\%). This is almost consistent with findings in Hawasa which state the items that caused the injuries was syringe needle (54.4\%) and a glass item (37.3\%) [19] And also similar with study done in Saudi Arabia in which syringe related activities were associated with more sharp injuries [17]. According to this study the prevalence of sharp injuries was higher among diploma nurses $(40.5 \%)$, followed by laboratory technicians and diploma midwifery respectively. This was also similar with study conducted in Hawasa in which the occurrence of sharp injuries among diploma nurses $(30.3 \%)$ was the highest, followed by laboratory technicians and other professionals [19, 17]. This can be explained by the fact that nurses administer most of the injections and are responsible for venipunctures, IV administrations and other procedures.

According to this result, the activities associated with sharp injuries in the last one year were recapping of needle (53.6\%), 48.2\% during suturing, and failure to adhere to Ups $(33.9 \%)$. This finding was consistent with findings done in India, in which the commonest clinical activity to cause the SI was recapping of needle (55\%), and suturing (46.9\%).

The risk factors associated with SIs were work experience, working $>35$ hours per week, lack of training at work place on such injuries, poor practice level, night shift work, negative attitude and recapping of needles. This is similar with study conducted in Kampala, in which the risk factor for sharp injuries was lack of training on such injuries, working for more than 40 hour/week, recapping needles most of the time, in Three Hospitals in Kunming, China night shifts, in Sub-Saharan Africa, not having attended any training session on such injuries in the workplace, having work experience 
for less than 10 years, working long hours, recapping needles all or most of the time and in Pakistan, work experience were associated with receiving sharp injuries during the previous 6 months. In Mongolia, worked longer than 35 hours per week, less working experience, and administered more than 10 injections per day were reported as a factors. Study from three hospitals in Kunming, china report working night shift.

\section{Conclusion}

The prevalence of sharp injury in western wollega public hospitals is $56(32.9 \%)$ within the last one year. The most important factors that cause needle stick and sharp injury were lack of training, hours worked per week, number of injection per day, work experience, poor practice, negative attitude, night shift work and recapping of needle were identified as predictor's factors for sharp injuries. Further prospective studies on large scale are recommended to determine the cause and effect relationship of factors affecting sharp injuries among HCPs in hospital setting.

Safe handling and disposal of needle stick and sharp materials enable preventing blood borne infections. Therefore, health care providers should get training to fill the skill gap, apply universal precaution during procedure, and never recap needles after use.

\section{Competing Interests}

The authors declare that they have no competing interests.

\section{Acknowledgements}

We would like to thank all staffs of western Wollega public hospitals, Jimma University for their support during the study, and Jimma University for financing the research.

\section{References}

[1] Cheng HC, Su CY, Yen AMF, Huang CF (2012) Factors Affecting Occupational Exposure to Needle stick and Sharps Injuries among Dentists in Taiwan: A Nationwide Survey, PLOS ONE.

[2] Memish ZA, Assiri AM, Eldalatony MM, Hathout HM, Alzoman H, et al. (2013) Risk analysis of needle stick and sharp object injuries among health care workers in a tertiary care hospital (Saudi Arabia). J Epidemiol Glob Health 3: 123-129.

[3] Kebede G, Molla M, Sharma HR (2012) Needle stick and sharps injuries among health care workers in Gondar city, Ethiopia. Safety Science 50: 1093-1097.

[4] Desalegn B, Beyene H, Yamada R (2012) Patients-tohealthcare workers HIV transmission risk from sharp injuries, Southern Ethiopia. SAHARA J 9: 1-5.

[5] WHO/UNICEF, 2015. Water, sanitation and hygiene in health care facilities: status in low- and middle-income countries. World Health Organization, Geneva.
[6] Jahangiri M., Rostamabadi A., Hoboubi N., Tadayon N., Soleimani A. Needle stick injuries and their related safety measures among nurses in a University Hospital, Shiraz, Iran. Saf Health Work. 2016; 7 (1): 72-77.

[7] Yeshitila M, Mengistie B, Demessie A and Godana W (2015). Prevalence and Associated Factors of Needle Stick Injury among Nursing and Midwifery Students an Haramaya and Jigjiga University, Eastern Ethiopia

[8] Manyele SV, Anicetus H, Bilia MH. (2012) "Globalization and its effects on Medical Waste Management in Tanzania" IET Annual Conference and General Meeting, AICC Arusha, Tanzania.

[9] Pruss-U stun A., Rapiti E. \& Hutin Y (2010). Sharps Injuries: Global Burden of Disease from Sharps to Health-care Workers. WHO, Geneva, (pp. 1-40).

[10] Chan H., Bachok B (2013). Analysis of sharps injury occurrences at a hospital in Singapore. International Journal of Nursing Practice. (pp 274-281).

[11] Panlilio L., Cardo M., Campbell S., Srivastava U., Jagger H., Orelien G (2012). Estimate of the annual number of percutaneous injuries in U.S. healthcare workers. In: Program and abstracts of the 4th International Conference on Nosocomial and Healthcare-Associated Infections; Atlanta, (pp: 61).

[12] Müller-Barthelm R., Buchholz L., Nübling M., Häberle E (2011). Quality control of devices with needle protection technology. Arbeitsmed Sozialmed Umweltmed (pp: 210 217).

[13] Mantel C. from assessment to planning: injection safety assessments coordinated by the WHO Department of Vaccines and Biological in the Eastern Mediterranean region, Safe Injection Global Network. Annual Meeting Report, 2010.

[14] Davis MS (2011). Advanced Precautions for Today's OR: The Operating Room Professional's Handbook for the Prevention of Sharps Injuries and Blood borne Exposures. Sweinbinder Publications LLC: Atlanta. 2nd ed. (pp 53-63).

[15] Doebbeling, N., Vaughn, D., McCoy, E. Beekmann, F. Woolson, J., Torner. C (2013). Percutaneous injury, blood exposure, and adherence to standard precautions: are hospitalbased health care providers still at risk? Clin. Infect. Dis (pp 1006-1013).

[16] World Health Organization: The world health report: Reducing risks, promoting healthy life. Geneva: World Health Organization; 2002.

[17] Efetie E., Salami A (2009). Prevalence of, and attitude towards, needle-stick injuries by Nigerian gynecological surgeons. Niger J Clin Pract; (pp 34-6).

[18] Department of Health. Procedure for management of needle sticks injury or mucosal contact with blood or body fluids. Available from www. info.gov.hk/aids/pdf/g38.pdf(2011).

[19] Lachowicz R., Mathews P (2009). The pattern of sharps injury to health care workers at Witbank Hospital. S Afr Fam Pract; (pp 48-51).

[20] Honda M., Chompikul J., Rattanapan C., Wood G., Klungboonkrong S (2011). Sharps Injuries among Nurses in a Thai Regional Hospital: Prevalence and Risk Factors. (pp 24). 